The first two chapters deal with the anatomy and experimental physiology of the part under discussion. Usually the most precise and unyielding part of medicine, the anatomy here is uncertain and shifting, the very delineation of the temporal lobe being artificial. This meagre map, peppered with confusing synonyms, is no fault of the author; so far as it is possible Dr. Critchley clarifies it. The subsequent nine chapters are given over to a discussion of the divers symptoms that may arise from parietal lobe disease, each one devoted to a single symptom complex. The sense of touch, motility, vision, speech, the body image, spacial cognizance and others are taken and examined with minute care. A further chapter, a most valuable one, is concerned with the relationship of parietal symptoms to dementia and hysteria. Finally there is an excellent summing up and à most carefully prepared selective bibliography containing over rooo references.

Throughout the discussion of symptomatology we are informed in the smallest detail, not only from the author's rich experience but by his catholic selection of the world literature. Indeed the reader may often wish that the author had been less generous in quoting so many workers in this field for the synonyms and neologisms left by them as tiny monuments of their labours are confusing. The chapter on psychiatric considerations is much more free of these obstructions and this reads with a stimulating straightforwardness that is shared by the summing-up chapter. Too often we have to pay such strict attention to the precise meaning of a changed prefix or other syllable that we lose the thread of meaning. This, however, is captious criticism and may seem small thanks for the tremendous labour that has gone into this book. Dr. Critchley has undertaken a stupendous task with a clear knowledge of his responsibility to the reader in presenting considered samples of many differing views. He has made it abundantly clear that if traditional neurological methods are to probe successfully for greater knowledge in this sphere then they must be applied more widely and with greater imagination than by routine tests hitherto used. He warns against the stultifying and almost certainly inaccurate view of static functional specificity in the cortex and emphasises the evidence for its flexibility and resilience. After reading of the polyglot eloquence of the parietal lobe it will come as a surprise to many that a mere half century ago it was considered as a ' silent' part of the brain. Now it seems that if no one part of the brain may be said to specialize in understanding, or when diseased give rise to misunderstanding, it is the parietal lobe.

Dr. Critchley must be warmly thanked for this monograph, a standard reference book, a stimulating though difficult book to read on a confusing part of neurology.

\section{DIURETIC THERAPY}

By Alfred Vogl, M.D. Pp. xiv + 248. London: Baillière, Tindall \& Cox, Ltd. 1953. 38s. 6d.

This rather small but very expensive volume offers a practical guide to diuretic therapy, and contains a great deal of information which is otherwise only available scattered in textbooks of medicine, treatment and pharmacology. The value of.. the most recent measures is emphasized, though it $\overrightarrow{\vec{B}}$ was published too early for the inclusion of such $\stackrel{\text { ? }}{\rightarrow}$ an interesting recent development as the use of $\bar{c}$ '6063.' The book contains a practical section on dietary measures, several case reports indicating $\frac{\omega}{s}$

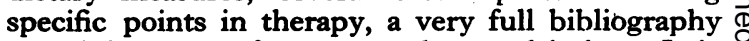
containing 725 references, and a good index. It is clearly written, and the information appears accurate 0 and authoritative.

\section{MEDICAL AND SCIENTIFIC INVESTIGATIONS IN THE CHRISTIE CASE}

By Francis E. Camps, M.D. Pp. xxiii +244 , with 53 illustrations, 6 in colour. London: Medical

Publications, Ltd. 1953. 30s.
The importance of this book is enhanced by its $\mathrm{D}$ having been published while the Christie case is $\dot{\omega}$ still fresh in our memories. Despite this speed $\mathrm{N}$ there are remarkably few errors. Small slips occur 을 in the second table on page 21 and in line 127 on page 131 , and the quotation on page 146 on the effect of trauma in life on decomposition is undoubtedly false.

Dr. Camps has sifted the information available most carefully and presents it in a pleasant logicad way. He starts with a summary of the outstanding. events, devotes a few paragraphs to relevant in formation regarding the scene of the murders at ro Rillington Place, and then embarks upon a description of the extensive pathological, anatomical and dental investigation of the four female bodies and the two female skeletons discovered.

A pictorial method is used very effectively to indicate where the various bones were discovered in the garden, and the interpretation of the methods used to determine the time of death and burial is wisely conservative.

Here there is a necessary digression to introduce the examination of the exhumed body of Mrs. Beryl Evans, whose husband was hanged for murdering her at 1o Rillington Place in 1950 . The reexamination confirmed that in contrast to at least three of Christie's victims, carbon monoxide was not a factor in Mrs. Evans's death. Undoubtedly the fate of blood pigments in decaying flesh requires fuller investigation.

The next chapter, which is almost self standing, is a review of carbon monoxide poisoning based upon the extensive knowledge of an expert on coal gas.

The picture of what actually happened to the dead women as deduced from these investigations $\varphi$ and Christie's statements remains a little vague. Some of the evidence suggests that there were other $\stackrel{D}{?}$ women involved and extraordinarily interesting confirmation might be obtained from one of those who escaped.

The climax of the case, the trial of Christie, is described in some detail, and particularly important 